\title{
Increasing the Ability of Indonesian in Determining Story Elements by Applying Concept Mapping Methods Assisted by Graphic Media
}

\section{Carsinem}

\author{
SD Negeri 5 Gumelar \\ carsinemcaca@gmail.com
}

\section{Article History \\ accepted 14/11/2020}

approved $21 / 11 / 2020$ published $26 / 11 / 2020$

\begin{abstract}
The purpose of this study is to improve Indonesian language skills in determining the elements of the story by applying the concept mapping method assisted by graphic media. The research conducted was a Classroom Action Research (CAR) in two cycles, with each cycle consisting of one meeting. In cycle I, the results of student activities through evaluation were obtained from all students as many as 35 students, there were 20 students completed and 15 students had not completed, with a persetanse of $57 \%$ and $43 \%$. In the second cycle, it was decided that the students experienced an increase in completeness as expected. In cycle II, there were 29 students who had completed and 6 students who had not yet completed, with a percentage of $83 \%$ and $17 \%$. The application of the Concept Mapping learning model can improve the learning outcomes of Class 4 students in Indonesian muples in determining the elements of the story. Students will always remember as provisions for the future in everyday life, students are able to determine the elements of the story correctly.
\end{abstract}

Keywords: The ability to determine, concept mapping, Indonesian

\begin{abstract}
Abstrak
Tujuan dari penelitian ini adalah untuk peningkatan kemampuan bahasa indonesia dalam menentukan unsur cerita dengan menerapkan metode concept mapping berbantu media grafis. Penelitian yang dilakukan adalah Penelitian Tindakan Kelas (PTK) sebanyak dua siklus, dengan setiap siklusnya terdiri dari satu pertemuan. Pada siklus I hasil kegiatan siswa melalui evaluasi didapatkan dari seluruh siswa sebanyak 35 siswa terdapat 20 siswa Tuntas dan 15 Belum Tuntas, dengan persetanse $57 \%$ dan $43 \%$. Pada siklus II maka diputuskan bahwa siswa mengalami peningkatan ketuntasan sesuai yang diharapkan. Pada siklus II terdapat 29 siswa yang sudah Tuntas dan 6 siswa Belum Tuntas, dengan persentase 83\% dan 17\%. Penerapan model pembelajaran Concept Mapping dapat meningkatkan hasil belajar peserta didik Kelas 4 pada mupel Bahasa Indonesia dalam menentukan unsur cerita. Peserta didik akan selalu teringat sebagai bekal untuk masa depan dalam kehidupan sehari-hari, peserta didik mampu menentukan unsur cerita dengan benar.
\end{abstract}

Kata kunci: Kemampuan menentukan, concept mapping, Bahasa Indonesia $\begin{array}{ll}\text { Social, Humanities, and Education Studies (SHEs): Conference Series } & \text { p-ISSN 2620-9284 } \\ \text { https://jurnal.uns.ac.id/shes } & \text { e-ISSN 2620-9292 }\end{array}$ 


\section{PENDAHULUAN}

Bahasa merupakan sarana untuk saling berkomunikasi, saling berbagi pengalaman, saling belajar dari yang lain dan untuk meningkatkan kemampuan intelektual. Hal ini berarti bahwa bahasa memiliki peran yang penting bagi manusia.Dengan demikian, dapat dimaklumi jika di sekolah terdapat mata pelajaran bahasa,khususnya bahasa Indonesia. Mata pelajaran bahasa Indonesia merupakan salah satu sarana yang dapat mengakses berbagai informasi dan kemajuan tersebut. Untuk itu, kemahiran berkomunikasi dalam bahasa Indonesia secara lisan dan tertulis harus benar- benar dimiliki dan ditingkatkan. Oleh sebab itu, seorang guru dituntut untuk mampu mencapai kompetensi dasar yang sudah ditetapkan. Selanjutnya Zaenal Arifin mengatakan bahwa di dalam kedudukannya sebagai bahasa nasional, Bahasa Indonesia berfungsi (1) lambang kebanggaan, (lambangidentitas nasional, (3) alat perhubungan antar warga, antar daerah, dan antar budaya, dan (4) alat yang memungkinkan penyatuan berbagai- bagai suku bangsa dengan latar belakang sosial budaya dan bahasanya masing masing ke dalam kesatuan kebangsaan Indonesia.

Sebagai lambang kebanggaan kebangsaan, bahasa Indonesia mencerminkan nilai-nilai sosial budaya yang mendasari rasa kebangsaan kita. Atas dasar kebanggaan ini, bahasa Indonesia kita pelihara dan kita kembangkan serta rasa kebanggaan pemakainya senantiasa kita bina. Mata pelajaran Bahasa Indonesia merupakan salah satu sarana yang dapat mengakses berbagai informasi. Untuk itu kemahiran berkomunikasi dalam Bahasa Indonesia secara lisan dan tertulis harus benar-benar dimiliki dan ditingkatkan. Oleh sebab itu seorang guru dituntut untuk mampu mencapai kompetensi dasar yang sudah ditetapkan. Pembelajaran bahasa Indonesia di sekolah diarahkan untuk meningkatkan kemampuan siswa dalam berkomunikasi dengan bahasa Indonesia, baik secara lisan maupun tulisan. Untuk mewujudkannya maka pelajaran bahasa Indonesia diprogramkan untuk mengembangkan pengetahuan, sikap positif terhadap bahasa Indonesia dan keterampilan berbahasa. Adapun keterampilan berbahasa dalam kurikulum terdiri atas empat aspek, yaitu keterampilan menyimak, keterampilan berbicara, keterampilan membaca, dan keterampilan menulis.

Sebagaimana dikemukakan oleh Tarigan bahwa cerita dibangun oleh unsur-unsur intrinsik (unsur yang membentuk karya sastra dari dalam karya itu sendiri ). Unsur intrinsik cerita yaitu, sebagai berikut: 1) tema, 2) alur, 3 ) perwatakan, 4) latar, dan 5) pusat pengesahan. Dengan kata lain suatu cerita dikatakan baik apabila didalamnya terkandung unsur-unsur tersebut.

Berdasarkan hasil pengamatan selama penulis bertugas di kelas IV SD Negeri 5 Gumelar tahun ajaran 2020/2021 ditemui gejala-gejala atau fenomena khususnya pada aspek kemampuan mengidentifikasi unsur-unsur cerita seperti:

1. Rendahnya kemampuan siswa dalam mengidentifikasi unsur-unsur cerita. Dari 35 orang siswa hanya 13 orang yang dapat bercerita dengan baik, sedangkan sisanya belum dapat mengidentifikasi unsur-unsur cerita dengan baik.

2. Kurangnya pemahaman siswa dalam memahami aspek-aspek yang terkandung dalam suatu cerita. Seperti anak tidak dapat menyebutkan tema, alur dan sebagainya.

3. Siswa kesulitan dalam menentukan unur-unsur cerita dan kurang kinginannya untuk bertanya pada guru. 
Dari fenomena-fenomena atau gejala-gejala tersebut di atas, terlihat rendahnya kemampuan siswa dalam mengidentifikasi unsur-unsur cerita. Keadaan ini menurut analisis penulis dipengaruhi oleh cara guru mengajar yang kurang sesuai dengan materi yang diajarkan. Guru cenderung menyampaikan materi dengan ceramah ataupun hanya dengan memberikan tugas kepada siswa sehingga siswa menjadi pasif.

Berkaitan dengan hal-hal yang dikemukakan di atas, maka peneliti mengambil judul penelitian Peningkatan Kemampuan Bahasa Indonesia Dalam Menentukan Unsur Cerita Dengan Menerapkan Metode Cocept Mapping Berbantu Media Grafis Kelas IV SD Negeri 5 Gumelar Tahun Ajaran 2020/2021

Identifikasi masalah dari latar belakang di atas yaitu (a) Rendahnya motivasi belajar dan berpikir kritis peserta terhadap pembelajaran Bahasa Indonesia; (b) Sebagian pendidik dalam menyampaikan materi pelajaran Bahasa Indonesia masih menggunakan pembelajaran konvesional yang masih berpusat pada pendidik; (c) Kurangnya alat media sebagai pembantu sarana dan prasarana dalam penyampaian materi pembelajaran Bahasa Indonesia.

Berdasarkan hasil pengamatan selama penulis bertugas di kelas IV SD Negeri 5 Gumelar tahun ajaran 2020/2021 ditemui gejala-gejala atau fenomena khususnya pada aspek kemampuan mengidentifikasi unsur-unsur cerita seperti: (a) Rendahnya kemampuan siswa dalam mengidentifikasi unsur-unsur cerita. Dari 35 orang siswa hanya 13 orang yang dapat bercerita dengan baik, sedangkan sisanya belum dapat mengidentifikasi unsur-unsur cerita dengan baik; (b) Kurangnya pemahaman siswa dalam memahami aspek-aspek yang terkandung dalam suatu cerita. Seperti anak tidak dapat menyebutkan tema, alur dan sebagainya; (c) Siswa kesulitan dalam menentukan unur-unsur cerita dan kurang kinginannya untuk bertanya pada guru.

Rumusan penelitian berdasarkan latar belakang di atas yaitu (a) Bagaimana upaya peningkatan kemampuan dalam menentukan unsur cerita dengan menerapkan metode Cocept Mapping Berbantu Media Grafis Kelas IV SD Negeri 5 Gumelar Tahun Ajaran 2020/2021? dan (b) Apakah penggunaan metode Cocept Mapping Berbantu Media Grafis dapat meningkatkan kemampuan dalam menentukan unsur cerita siswa kelas IV SD Negeri 5 Gumelar?

Berdasarkan rumusan masalah diatas, tujuan dalam penelitian ini adalah sebagai berikut: (a) Menjelaskan penerapan Metode Cocept Mapping Berbantu Media Grafis dalam upaya meningkatkan kemampuan dalam menentukan unsur cerita pada siswa kelas IV SDN 5 Gumelar. (b) Mengetahui penggunaan Metode Cocept Mapping Berbantu Media Grafis dapat meningkatkan sikap percaya diri dan kemampuan dalam menentukan unsur cerita pada siswa kelas IV SDN 5 Gumelar. Penelitian ini merupakan salah satu usaha untuk memperdalam dan memperluas ilmu pengetahuan penulis dan dapat memberikan manfaat untuk meningkatkan kemampuan guru untuk menciptakan proses pembelajaran yang efektif dan efisien.

\section{METODE}

Penelitian ini adalah penelitian tindakan kelas (Classroom Action Research) dengan menerapkan model pembelajaran Concept Mapping. Concept Mapping adalah suatu konsep yang disajikan berupa kaitan- kaitan yang bermakna antara konsep-konsep dalam bentuk proposisi. Konsep- konsep tersebut dikaitkan dengan kata-kata tertentu sehingga akan saling keterkaitan. Concept Mapping lebih menunjuk pada penuangan ide ide pikir sebagai catatancatatan dalam bentuk grafis sebagai salah satu teknik belajar efektif. Concept Mapping ini dikembangkan oleh Tony Bozan pada 1970-an, yang didasarkan pada kerjannya otak. Otak kita mengingat informasi dalam bentuk gambar, symbol, bentuk-bentuk suara musik dan perasaan. Otak menyimpan informasi dengan pola dan asosiasi seperti pohon dengan cabang dan rantingnya. Concept Mapping menggunakan pengingat-ingat visual dan sensorik dalam suatu pola dalam ide-ide yang berkaitan, seperti peta jalan yang digunakan untuk belajar, mengorganisasikan, dan merencanakan. Mapping ini dapat membangkitkan ide-ide orisinal dan memicu ingatan dengan mudah, jauh lebih mudah dari pada pencatatan tradisional. Oleh karena itu, secara fungsional Concept Mapping diartikan sebagai teknik pemanfaatan 
keseluruhan otak dengan menggunakan citra visual dan prasarana grafis lainnya untuk membentuk kesan.

\section{HASIL DAN PEMBAHASAN}

Pada siklus I pembelajaran dilaksanakan selama satu pertemuan. Siklus I membahas tentang menentukan unsur cerita dengan menerapkan metode concept mapping berbantu media grafis. Siklus II membahas perbaikan tentang menentukan unsur cerita dengan menerapkan metode concept mapping berbantu media grafis. Berikut ini adalah hasil belajar peserta didik pada siklus I yang bisa dilihat pada tabel berikut.

Tabel 1. Hasil Belajar Peserta Didik Siklus 1

\begin{tabular}{ccccc}
\hline \multirow{2}{*}{ Siklus 1 } & \multicolumn{2}{c}{ Tuntas } & \multicolumn{2}{c}{ Belum Tuntas } \\
\cline { 2 - 5 } & $\mathrm{Jml}$ & $\%$ & $\mathrm{Jml}$ & $\%$ \\
\cline { 2 - 5 } & 20 & $57 \%$ & 15 & $43 \%$ \\
\hline
\end{tabular}

Pada siklus I hasil kegiatan siswa melalui evaluasi didapatkan dari seluruh siswa sebanyak 35 siswa terdapat 20 siswa Tuntas dan 15 Belum Tuntas, dengan persetanse 57\% dan $43 \%$. Berdasarkan pada siklus I maka diputuskan untuk melanjutkan perbaikan pada siklus II dikarenakan belum mencapai ketuntasan yang diharapkan. Berikut ini adalah hasil belajar peserta didik pada siklus II yang bisa dilihat pada tabel berikut.

Tabel 2. Hasil Belajar Peserta Didik Siklus 2

\begin{tabular}{ccccc}
\hline \multirow{2}{*}{ Siklus 2 } & \multicolumn{2}{c}{ Tuntas } & \multicolumn{2}{c}{ Belum Tuntas } \\
\cline { 2 - 5 } & $\mathrm{Jml}$ & $\%$ & $\mathrm{Jml}$ & $\%$ \\
\cline { 2 - 5 } & 29 & $83 \%$ & 6 & $17 \%$ \\
\hline
\end{tabular}

Berdasarkan pada siklus II maka diputuskan bahwa siswa mengalami peningkatan ketuntasan sesuai yang diharapkan. Pada siklus II terdapat 29 siswa yang sudah Tuntas dan 6 siswa Belum Tuntas, dengan persentase 83\% dan 17\%.

Dari 2 siklus yang sudah dilaksanakan selama 2 pertemuan dapat dipastikan bahwa model Concept Mapping dapat meningkatkan hasil belajar peserta didik pada mupel Bahasa Indonesia dalam menentukan unsur cerita dengan menerapkan metode concept mappin $\mathrm{g}$ berbantu media grafis Kelas 4 di SD Negeri 5 Gumelar. Dalam kehidupan sehari-hari, sering kita mendengar orang menyebutkan kata sastra anak, cerita anak atau bacaan anak. Santosa, dkk (2006:8.3) menyatakan bahwa: "Kata sastra anak merupakan dua buah kata yang dirangkaiakan menjadi satu kata sebut, yaitu dari kata sastra dan anak. Kata sastra berarti karya sei imajinatif dengan unsur estetisnya dominan yang bermediumkan bahasa. Karya seni imajinatif yang bermedium bahasa itu dapat dalam bentuk tertulis ataupun dalam bentuk lisan. Sementara itu kata anak disini diartikan sebagai manusia yang masih kecil. Tentu pengertian anak yang dimaksud disini bukan anak balita da bukan pula anak remaja, melainkan anak yang masih berumur antara 6 - 13 tahun, usia anak sekolah dasar. Jadi secara sederhana istilah sastra anak dapat diartikan sebagai karya seni yang imajinatif dengan unsur estetisnya domian yang bermedium bahasa baik lisan ataupun tertulis, yang secara khusus dapat dipahami oleh anak-anak dan berisi tentang dunia yang akrab dengan anak-anak.

Sementara itu istilah cerita anak menurut Santosa, dkk mengatakan bahwa istilah cerita anak merupakan istilah yang umum untuk menyebut sastra anak yang semata-mata bergenre prosa, seperti dongeng, legenda, mite yang diolah kemabli menjadi cerita anak dan tidak termasuk jenis puisi anak atau drama anak. Sedangkan istilah bacaan anak lebih menekankan pada media tertulis, bahasa tulis dan bukan bahasa lisan. Berdasarkan uraian di atas dapat disimpulkan bahwa cerita adalah tuturan yang memaparkan bagaimana terjadinya suatu hal ataupun karangan yang menuturkan perbuatan, pengalaman, penderitaan orang dan sebagainya, baik yang sungguh-sungguh terjadi maupun yang hanya rekaan belaka. Sehubungan dengan penelitian ini maka yang dimaksud cerita adalah cerita anak seperti yang telah dikemukakan sebelumnya. Sebagaimana dikemukakan oleh Tarigan bahwa cerita dibangun oleh unsur-unsur intrinsik (unsur yang membentuk karya sastra dari dalam 
karya itu sendiri ). Unsur intrinsik cerita yaitu, sebagai berikut: 1) tema, 2) alur, 3 ) perwatakan, 4) latar, dan 5) pusat pengesahan. Dengan kata lain suatu cerita dikatakan baik apabila didalamnya terkandung unsur-unsur tersebut. Dengan berbantu media grafis, Media grafis termasuk media visual, sebagaimana halnya media lain, media grafis berfungsi menyalurkan pesan dari sumber ke penerimaan pesan. Saluran yang dipakai menyangkut indra pengelihatan. Pesan yang akan disampaikan dituangkan ke dalam simbol-simbol komunikasi visual. Hal ini sesuai dengan konsep atau teori yang dikembangkan oleh Tony Bozan pada 1970-an, yang didasarkan pada kerjanya otak, mengingat informasi dalam bentuk gambar, symbol, bentuk-bentuk suara musik dan perasaan. Concept Mapping menggunakan pengingat-ingat visual dan sensorik dalam suatu pola dalam ide-ide yang berkaitan, seperti peta jalan yang digunakan untuk belajar, mengorganisasikan, dan merencanakan. Beberapa tujuan dari Metode Concept Mapping dalam pembelajaran yaitu:

a. Menyelidiki pengetahuan peserta didik.

b. Belajar bermakna membutuhkan usaha yang sungguh-sungguh dari peserta didik untuk menghubungkan pengetahuan baru dengan konsep- konsep relevan yang telah mereka miliki.

c. Mempelajari cara belajar

d. Belajar bermakna terjadi bila pembuatan peta konsep timbul dari keinginan peserta didik untuk memahami isi pelajaran dari diri peserta didik, bukan untuk memenuhi keinginan guru.

e. Menunjukkan hubungan antara ide-ide peserta didik dan membantu memahami lebih baik apa yang sudah dipelajari.

f. Agar peserta didik lebih terampil untuk menggali pengetahuan awal yang sudah dimiliki dan memperoleh pengetahuan baru sesuai dengan pengalaman belajar.

Dari concept mapping berbantu media grafis inilah banyak manfaat yang sangat mendukung dalam penerapan pembelajaran sesuai dengan karakteristik abad 21 yaitu siswa mampu membangun pengetahuannya sendiri, mengintegrasikan pengetahuan yang lama dan yang baru, sebagai pengganti ringkasan yang lebih praktis dan fleksibel, mempermudah pemahaman siswa dan guru untuk menyatukan presepsi yang sama, dapat meningkatkan kreativitas peserta didik dalam menentukan konsep, dan merupakan salah satu cara evaluasi pembelajaran.

\section{SIMPULAN}

Penerapan model pembelajaran Concept Mapping dapat meningkatkan hasil belajar peserta didik Kelas 4 pada mupel Bahasa Indonesia dalam menentukan unsur cerita. Peningkatan yang terjadi karena adanya kesan pembelajaran yang mendalam dari peserta didik terhadap materi yang diajarkan. Peserta didik akan selalu teringat sebagai bekal untuk masa depan dalam kehidupan sehari-hari, peserta didik mampu menentukan unsur cerita dengan benar. Berdasarkan penelitian yang telah dilaksanakan salah satu model pembelajaran yang harus dikuasai guru adalah Concept Mapping berbantu media grafis sesuai dengan tuntutan karakteristik pembelajaran pada abad 21. Guru tetap mengarahkan dan memantau proses belajar peserta didik agar tidak terjadi miskonsepsi dan peran guru tidak tergantikan oleh media elektronik yang digunakan dalam pembelajaran. Kesuksesan pembelajaran daring yang dilaksanakan selalu bekerja sama dengan orang tua dan bijak menyikapi semua proses kegiatan pembelajaran yang dilaksanakan.

\section{DAFTAR PUSTAKA}

Aprinastuti, Christiyanti, dkk. (2017). Prototipe Modul Pelatihan Model Pembelajaran Van Hiele dalam Konteks Pendidikan Karakter untuk Sekolah Dasar. Yogyakarta: Sanata Dharma University Press.

Arifin, Zainal. (2009). Evaluasi Pembelajaran: Teori dan Aplikasinya. Bandung: PT Remaja Rosdakarya.

Cangara, Hafied. (2011). Pengantar IImu Komunikasi. Jakarta: PT Raja Grafindo Persada. Daryanto dan Tasrial. (2012). Konsep Pembelajaran Kreatif. Yogyakarta: Gava Media. 
Hamalik, Oemar. (2013). Proses Belajar Mengajar. Jakarta: Bumi Aksara.

Hartinah, Siti. (2013). Pengembangan Peserta Didik. Bandung: PT Refika Aditama.

Haryono, Anung. (2012). Media Pendidikan Pengertian, Pengembangan dan Pemanfaatannya. Depok: Rajawali Pers.

Puji Santosa, dkk.(2005). Materi dan Pembelajaran Bahasa Indonesia SD. Jakarta: UT

Maulana, Rizki.(1991). Kamus Praktis Bahasa Indonesia. Surabaya: Lima Bintang

Santosa, Puji dkk. (2005). Materi dan Pembelajaran Bahasa Indonesia SD. Jakarta: UT

Slamet. (2007). Dasar-Dasar Pembelajaran Bahasa Dan Sastra Indonesia Di Sekolah Dasar. Surakarta: Lembaga Pengembangan Pendidikan (LPP) UNS dan UPT. Penerbitan danPercetakan UNS Press

Arikunto, Suharsimi. (2007). Penelitian Tindakan Kelas. Jakarta: Bumi Aksara. 